\title{
Finding the Area of a Major League Baseball Field
}

Jacob Courchaine

University of South Florida

\author{
Advisors: \\ Arcadii Grinshpan, Mathematics and Statistics \\ Scott Campbell, Chemical \& Biomedical Engineering \\ Problem Suggested By: Jacob Courchaine
}

Follow this and additional works at: https://digitalcommons.usf.edu/ujmm

Part of the Civil Engineering Commons, and the Mathematics Commons

UJMM is an open access journal, free to authors and readers, and relies on your support:

Donate Now

\section{Recommended Citation}

Courchaine, Jacob (2013) "Finding the Area of a Major League Baseball Field," Undergraduate Journal of Mathematical Modeling: One + Two: Vol. 5: Iss. 1, Article 7.

DOI: http://dx.doi.org/10.5038/2326-3652.5.1.7

Available at: https://digitalcommons.usf.edu/ujmm/vol5/iss $1 / 7$ 


\title{
Finding the Area of a Major League Baseball Field
}

\begin{abstract}
Using a Major League Baseball (MLB) baseball field template for guidelines, we estimate the cost of building the largest possible field accepted under MLB standards. This includes finding the areas of both the clay and grassy regions and determining how many bags of clay and fertilizer are required to cover the field.
\end{abstract}

Keywords

Baseball Field, Major League Baseball, Infield, Outfield

Creative Commons License

(c) (i) (9)

This work is licensed under a Creative Commons Attribution-Noncommercial-Share Alike 4.0 License. 


\section{PROBLEM STATEMENT}

A major league baseball field has a unique shape, and it is not a trivial task to find the area of the clay region in the infield or the grassy outfield. It is possible to find these areas by plotting the boundaries of the sections on a Cartesian plane, expressing the boundaries as functions, and integrating the boundary equations.

\section{MOTIVATION}

We wish to find the area of the clay and grassy areas of the baseball field to know how many bags of clay and fertilizer an engineer or contractor would need in order to cover the entire

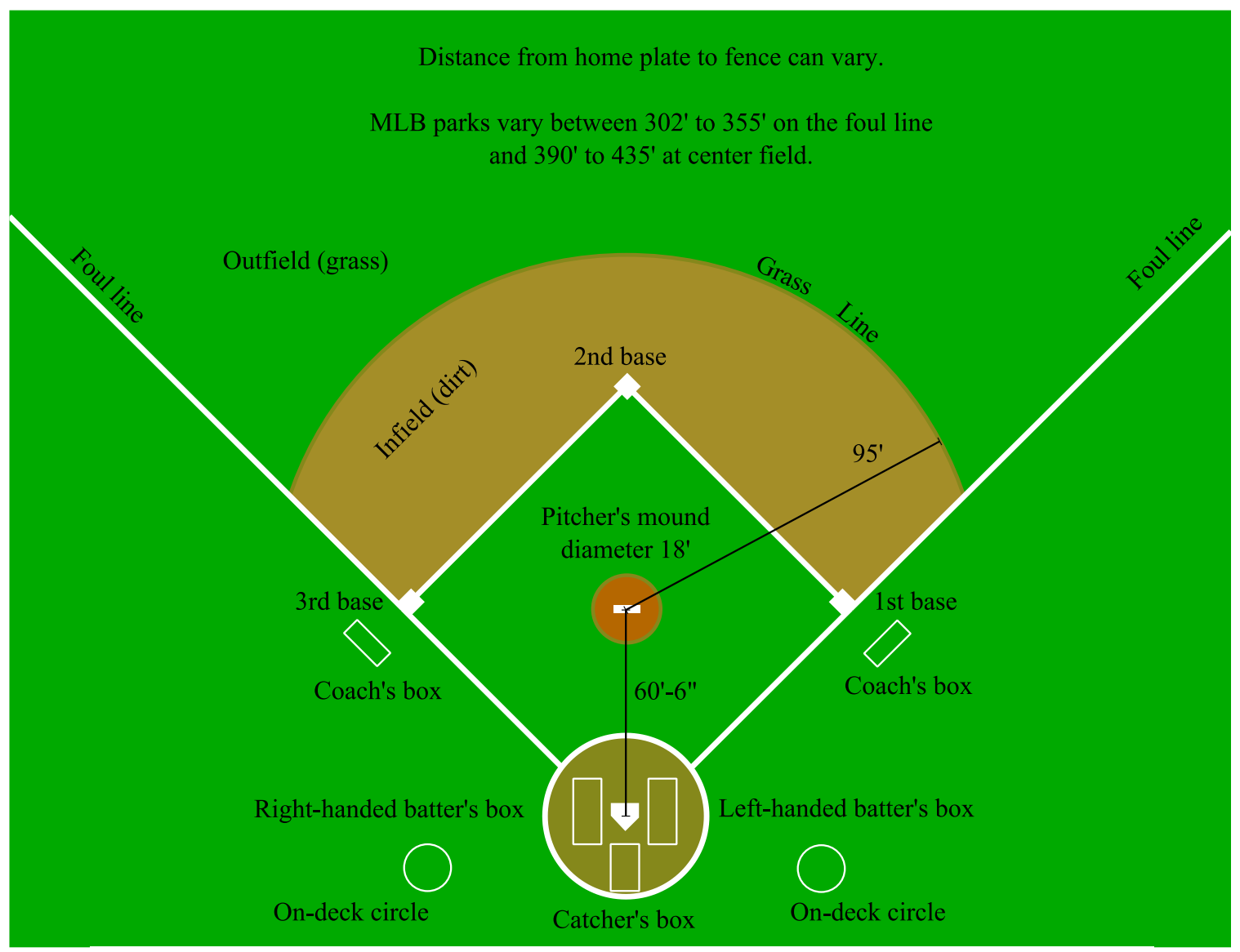

Figure 1: Infield dimensions for the template baseball field. 
baseball diamond, thus approximating the cost of building a baseball field.

\section{MATHEMATICAL DESCRIPTION AND SOLUTION APPROACH}

We consider a template baseball field with dimensions given in Figure 1. Further, we assume the outfield boundary is shaped like an ellipse, formed from setting outermost foul lines at $355 \mathrm{ft}$ and taking the center field distance to be $435 \mathrm{ft}$.

In order to find the sum of the clay and grassy areas, we first divide the field into five distinct parts (see Figure 2) and consider the regions separately. The areas for the home plate mound (1), the pitcher's mound (2), and the grass square at center field (3) can be found using elementary geometry. For the remaining two areas, we model the field as functions on a Cartesian plane, taking the

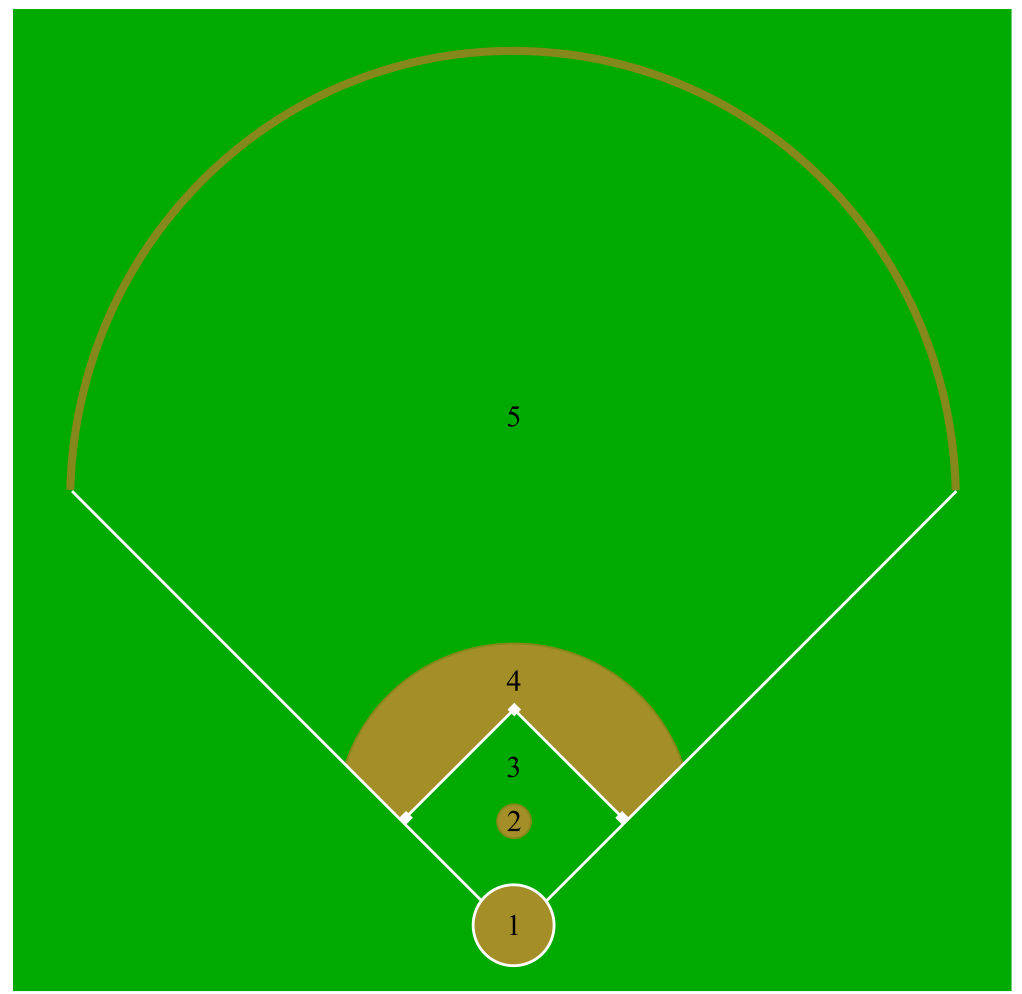

Figure 2: Field divided into five sections. pitcher's mound to be the origin. In this approach, we can use of the symmetry of the field to simplify the integral calculations.

Both the home plate and

pitcher's mounds are circular regions, and their areas are given by $A=\pi r^{2}$ where $A$ is the area and $r$ is the radius of the circle. The grassy infield is square except for its intersection with a quarter of the 
mound at home plate, so its area is given by $=l^{2}-\frac{1}{4} \pi r^{2}$, where $l$ is the length of the grass square, and $r$ is the radius of the mound at home plate. Using the dimensions given in Figure 1:

$$
\begin{aligned}
\text { Mound at home plate: } & \pi(13)^{2}=530.9 f t^{2} \\
\text { Pitcher's mound: } & \pi(9)^{2}=254.5 \mathrm{ft}^{2} \\
\text { Center field: } & (90)^{2}-\frac{1}{4} \pi(13)^{2}-\pi(9)^{2}=7,712.8 f t^{2}
\end{aligned}
$$

Next, we calculate the area of the clay section of the infield (4) by splitting it in half along an imaginary line from the home plate to the back of the centerfield (see Appendix, Figure 6). For ease of computation, we rotate the region so that the $x$-axis passes through second base and the $y$-axis passes through third base (see Figure 3). Note that the positions of second and

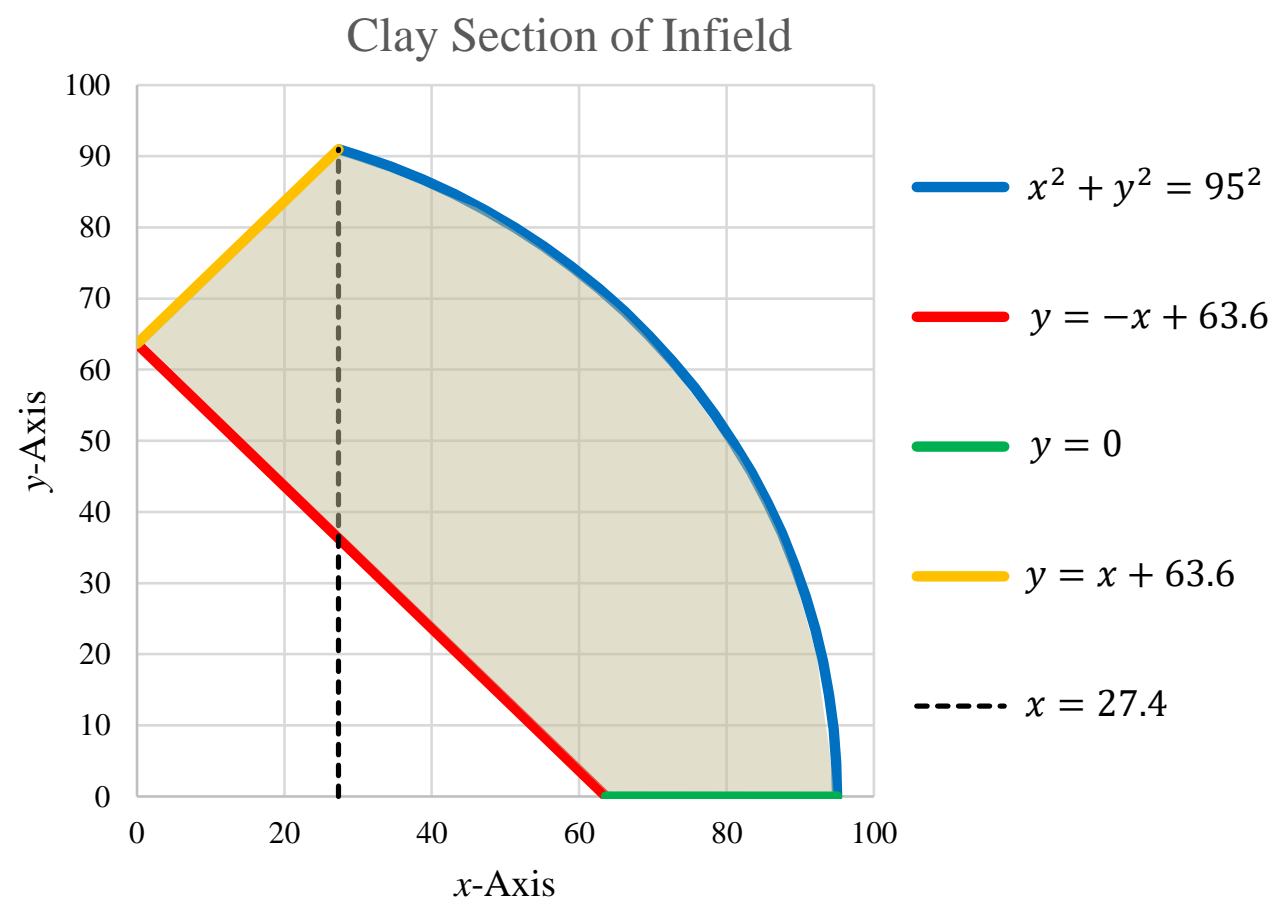

Figure 3: Clay section of infield cut in half and rotated $\mathbf{9 0}^{\circ}$. 
third base form a $45^{\circ}-45^{\circ}-90^{\circ}$ degree right triangle with a $90 \mathrm{ft}$ hypotenuse, i.e. each base is $45 \sqrt{2} \approx 63.6 f t$ away from the pitcher's mound.

Since the base and foul lines are perpendicular, the slope of the lines in the model will also be perpendicular, namely $y=x+63.6$ and $y=-x+63.6$. The outer boundary of the infield is given as a circular section with radius $95 \mathrm{ft}$ from the pitcher's mound which translates to the function $x^{2}+y^{2}=95^{2}$. Setting $x+63.6=y=\sqrt{95^{2}-x^{2}}$ yields the intersection of the top two functions at $x \approx 27.4$. Hence the clay area of the infield is given by:

$$
\begin{aligned}
A & =\int_{0}^{27.4}[(x+63.6)-(-x+63.6)] d x+\int_{27.4}^{95}\left[\sqrt{95^{2}-x^{2}}-(-x+63.6)\right] d x \\
& +\int_{63.6}^{95}(-x+63.6) d x \\
& =\left[x^{2}\right]_{0}^{27.4}+\left[\frac{1}{2}\left(x\left(\sqrt{95^{2}-x^{2}}+x-127.2\right)+95^{2} \sin ^{-1}\left(\frac{x}{95}\right)\right)\right]_{27.4}^{95} \\
& +\left[\frac{-x^{2}}{2}+63.6 x\right]_{63.6}^{95}=[5,110.5-492.98] f t^{2}=4,617.52 f t^{2}
\end{aligned}
$$

Doubling this section gives the total area of the clay section of the infield as

$$
A_{\text {infield }}=2 \times 4,617.52=9,235.04 f t^{2}
$$

Finally, we find the area of outfield by once again dividing it in half and rotating the section by $90^{\circ}$ (see Appendix, Figure 7). We model the far border of the outfield as an ellipse for the form

$$
\frac{(x-h)^{2}}{a^{2}}+\frac{(y-k)^{2}}{b^{2}}=1
$$

where $(h, k)$ is the center of the ellipse with major and minor radii $a$ and $b$. Since the bisection of the outfield is in line with the pitcher's mound (the origin), $k=0$. We assume that the center 


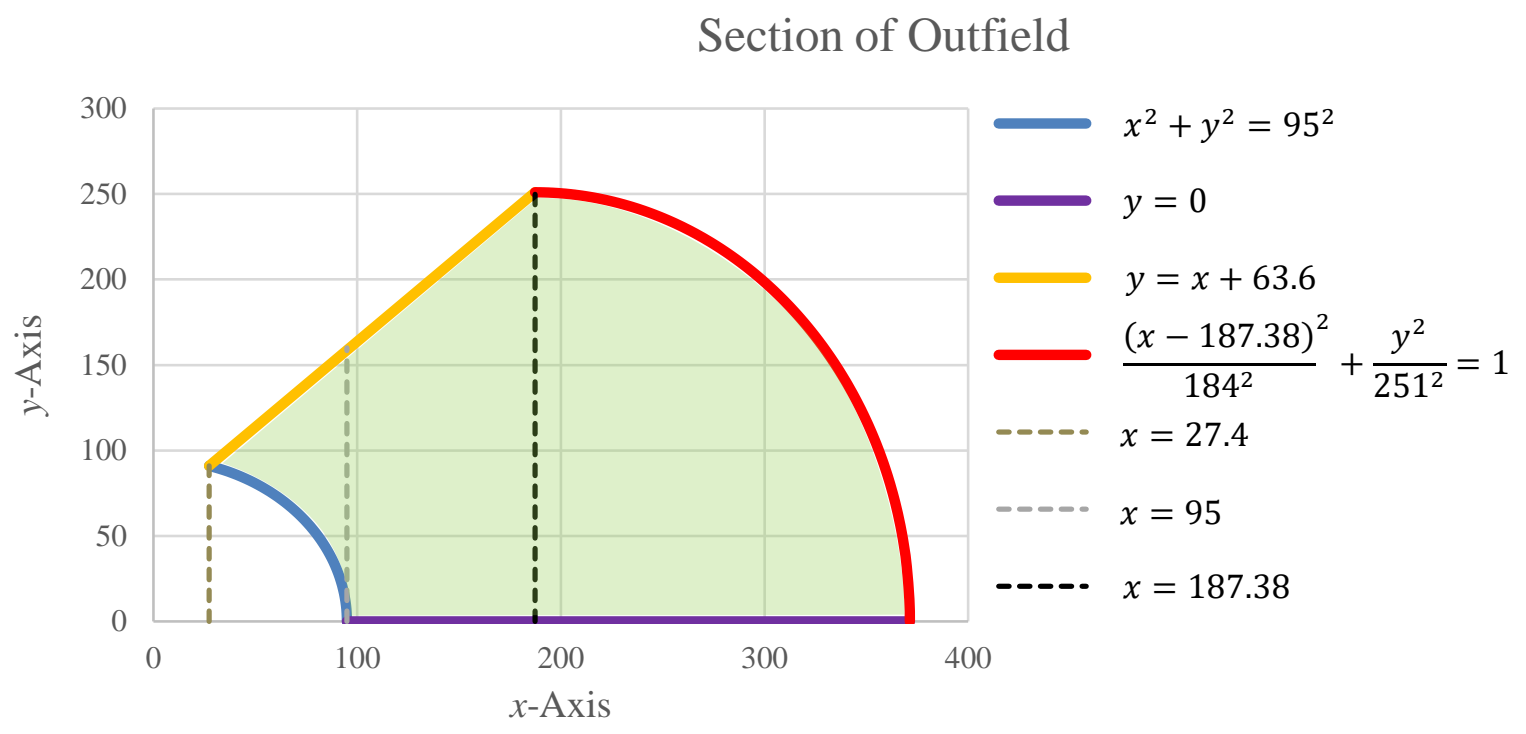

Figure 4: Section of outfield cut in half and rotated $90^{\circ}$.

of the outfield ellipse, the center of the home plate mound, and the end of the foul line forms a $45^{\circ}-45^{\circ}-90^{\circ}$ right triangle, so $h=\frac{355}{\sqrt{2}}-\frac{90}{\sqrt{2}} \approx 187.38$ (since the pitcher's mound is the origin). Now we use the information that it is $435 \mathrm{ft}$ from the center of the home plate mound to the centerfield wall, i.e., $\left(435-\frac{90}{\sqrt{2}}, 0\right) \approx(371.36,0)$ is a point on the ellipse. Further, the foul line terminates at the point $\left(\frac{355}{\sqrt{2}}-\frac{90}{\sqrt{2}}, \frac{355}{\sqrt{2}}\right) \approx(187.38,251)$. Putting the center and these two points into the equation for the ellipse yields the outfield formula:

$$
y=\sqrt{251^{2}-\left(\frac{251^{2}}{184^{2}}\right)(x-187.38)^{2}}
$$

Breaking up the region pictured above in Figured 4 into three pieces, the area is

$$
A=\int_{27.4}^{95}\left[(x+63.6)-\sqrt{95^{2}-x^{2}}\right] d x+\int_{95}^{187.38}(x+63.6) d x+\int_{187.38}^{371.36} \sqrt{251^{2}-\left(\frac{251^{2}}{184^{2}}\right)(x-187.38)^{2}} d x
$$




$$
\begin{aligned}
&=\left[\frac{x^{2}}{2}+63.6 x-\right.\left.\frac{1}{2} x \sqrt{95^{2}-x^{2}}-\frac{95^{2}}{2} \sin ^{-1} \frac{x}{95}\right]_{27.4}^{95}+\left[\frac{x^{2}}{2}+63.6 x\right]_{95}^{187.38} \\
&+\frac{251}{2}\left[(x-187.38) \sqrt{1-\left(\frac{187.38^{2}}{184^{2}}\right)+2\left(\frac{187.38}{184^{2}}\right) x-\left(\frac{1}{184^{2}}\right) x^{2}}-184 \sin ^{-1}\left(\frac{187.38-x}{184}\right)\right]_{187.38}^{371.36} \\
&=59,106 .
\end{aligned}
$$

Doubling the section area to get the area of the entire outfield gives:

$$
A_{\text {outfield }}=2 \times 59,106=118,212 f t^{2}
$$

Lastly, we need to add up all the areas containing clay and grass separately in order to find out the number of bags of clay and fertilizer need to buy, hence the cost for the whole project. Using (1), (2), and (4), we can find the area of the clay to be

$$
\begin{aligned}
A_{\text {clay }} & =A_{\text {home }}+A_{\text {pitcher }}+A_{\text {infield }} \\
& =530.9+254.5+9,235.04=10,020.4 f t^{2},
\end{aligned}
$$

and from (3) and (5) the area of the grassy areas to be

$$
A_{\text {grass }}=A_{\text {center }}+A_{\text {outfield }}=7,712.8+118,212=125,924.8 \mathrm{ft}^{2} .
$$

Each bag of clay weighs $w_{\text {clay }}=50 \mathrm{lbs} .$, costs $\$ 5.95$, and covers approximately $20 \mathrm{ft}^{2}$ (Beamclay), so the cost to cover all the clay areas of the baseball field is

$$
\frac{10,020.4 f t^{2}}{20 f t^{2} / b a g}=501.22 \approx 501 \text { bags and } \quad 501 \times \$ 5.95=\$ 2,980.95
$$

Each bag of fertilizer weighs $w_{\text {fert }}=50$ lbs., costs $\$ 39.98$, and covers approximately $5,000 f t^{2}$. The cost of fertilizer needed to cover the grassy area is

$$
\frac{125,924.8 f t^{2}}{5,000 f t^{2} / b a g}=25.19 \approx 26 \text { bags and } \quad 26 \times \$ 39.98=\$ 1,039.48
$$


Therefore the overall cost to cover the baseball field is:

$$
\$ 2,980.95+\$ 1,039.48=\$ 4,020.43 \text { (tax not included) }
$$




\section{Discussion}

The cost of creating a MLB standard baseball field is at least $\$ 4,020$. The overall area of the field was calculated to be $136,931 \mathrm{ft}^{2}$. This makes intuitive sense as the shape of the field is approximately a quarter circle. Estimating the total area above and below by the closest and farthest distance from the home plate, respectively, we see that our calculation is appropriate:

$$
\frac{1}{4} \pi 355^{2} \approx 98,980<136,931<148,617 \approx \frac{1}{4} \pi 435^{2}
$$

We also note that 501 bags of clay and 26 bags of fertilizer will weigh approximately $14,326 \mathrm{lbs}$.

\section{CONCLUSION AND RECOMMENDATIONS}

It was found that at least 501 bags of clay and 33 bags of fertilizer are needed to cover a MLB baseball field, which would cost approximately $\$ 4,020$. This price does not include tax, the clay for running lanes, or the bases, to finish the field. 


\section{NOMENCLATURE}

$\underline{\text { Area Integration }}$

$\begin{array}{lll}A & \text { Area } & f t^{2} \\ a & \text { Starting interval } & f t \\ b & \text { Ending interval } & f t\end{array}$

$\underline{\text { Areas of Geometric Shapes }}$

$\begin{array}{lll}r & \text { Radius } & f t \\ l & \text { Length } & f t\end{array}$

$\underline{\text { Ellipse }}$

$h \quad$ Horizontal position of center from $f t$ origin

$k \quad$ Vertical position of center from origin $f t$

a Horizontal radius $f t$

$b \quad$ Vertical radius $f t$

Equivalent Ratios

weight $\quad l b$ 


\section{REFERENCES}

Beamclay - Baseball Diamond Surfaces, Beamclay. New Jersey, 01 Jan 2012,http://www.beamclay.com/101 - Infields, Pitcher's Mounds, Batter's Boxes, Warning Tracks, Infield Conditioners and Drying Agents.pdf.

Burnett, Colin M.L. A baseball field drawn roughly to scale, Wikimedia Commons. 30 April 2012.

LESCO Landscape and Ornamental Fertilizer, Homedepot, Homer TLC, 2011, 3 May 2012. http://www.homedepot.com/h_d1/N-5yc1v/R-100133143/h_d2/ProductDisplay? catalogId=10053\&langId=-1\&keyword $=50 \mathrm{lb}$ grass fertilizer \&storeId $=10051$.

Stewart, James, Essential Calculus, Early Transcendentals, Belmont: Brooks Cole, 2011. 357-60.

Wolfram Alpha - Computational Knowledge Engine, Wolfram Alpha LLC, 2012. Web. 3 May 2012, http://www.wolframalpha.com

Wood, Elizabeth, Area Between Two Curves, Eastern Iowa Community College, EICC, n.d. 23 Apr 2012. 


\section{APPENDIX}

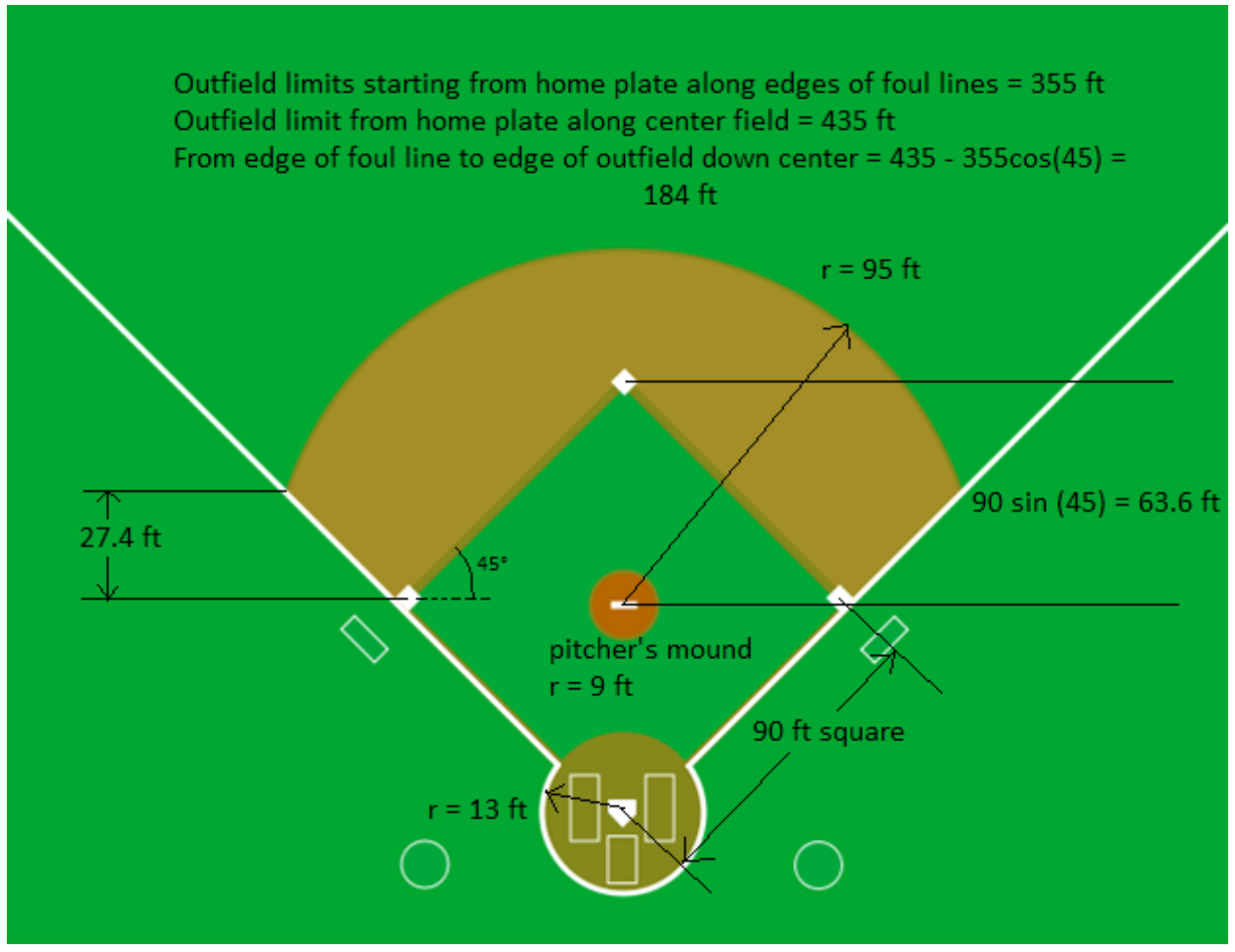

Figure 4: Sketch of a baseball field (Burnett, 2012)

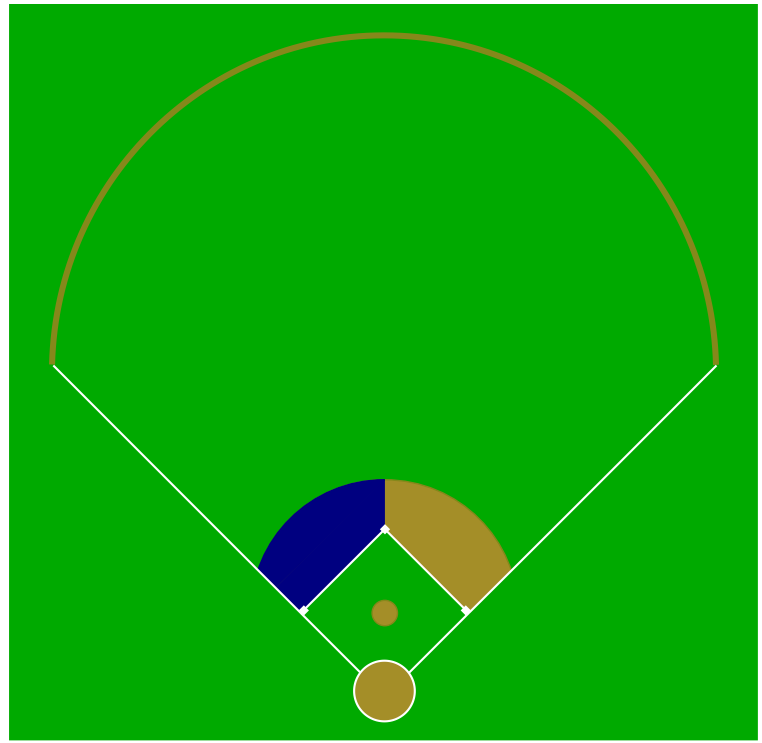

Figure 6: Half of the clay section of the infield.

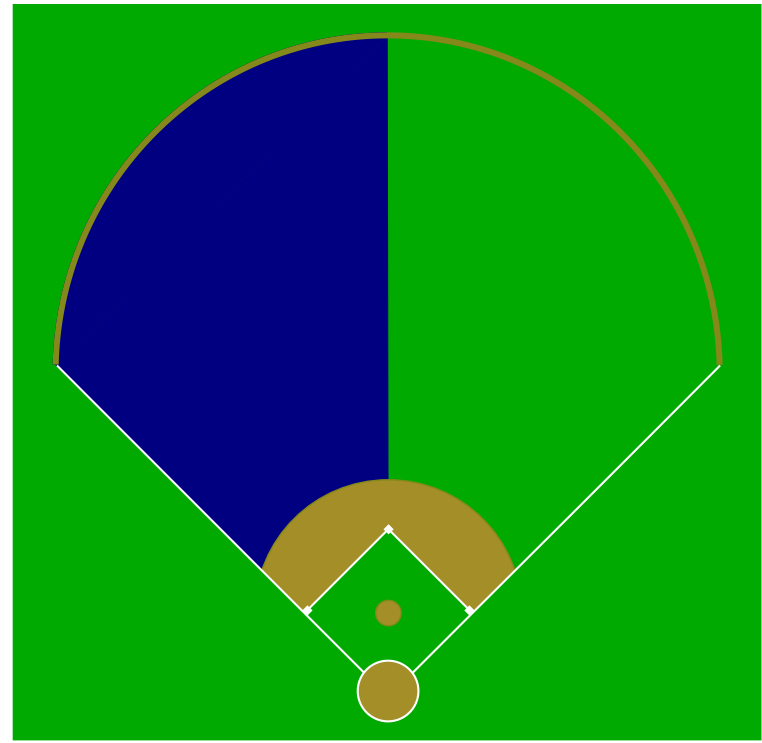

Figure 7: Half of the outfield. 


\section{Correction notice}

In May 2021 professor of mathematics and physics Michael Appelhans informed the editors of

UJMM and the author Jacob Courchaine that he found three following errors in this article:

1) The area of the rotated section needs THREE integrals:

(yellow-red) + (blue-red) + (blue-green). In the article, the author only uses the first two.

2) The equation of the circle is incorrect. Since the pitcher's mound is a few feet closer to Home plate $(3.14 \mathrm{ft})$, the center of the circle is at $(-3.14,0)$ and not the origin.

3) Lastly, due to the slight shift of the circle, the limits of the last integral change; the limit must also shift by $3.14 \mathrm{ft}$.

As to (1): the missed integral is added and the article is updated accordingly in July 2021.

As to (2) and (3): the author believes that no correction is needed. 